Marta Dudzińska1 , Jerzy S. Tarach², Agnieszka Zwolak1, 3 , Joanna Malicka², Mariusz Kowalczyk ${ }^{2}$, Joanna Świrska1 ${ }^{1}$, Jadwiga Daniluk ${ }^{1,3}$

${ }^{1}$ Chair of Internal Medicine and Department of Internal Medicine in Nursing, Medical University of Lublin

${ }^{3}$ Instiutute of Public Health, State School of Higher Education in Biala Podlaska

\title{
Quality of life among patients with type 2 diabetes after insulin therapy introduction: A prospective study
}

\section{ABSTRACT}

Introduction. In case of many patients with type 2 diabetes, despite deterioration of glycaemic control the moment of intensification of treatment is delayed because of barriers to initiating insulin therapy.

Aim. The aim of the study was an evaluation of changes on Health Related Quality of Life (HRQoL) after intensification of the treatment among group of type 2 diabetes patients.

Methods. The study involved 52 patients, treated so far by oral anti-diabetic drugs (OAD), for whom insulin was introduced. This group was exposed to 8 ( \pm 1.5$)$ months long observation. HRQoL was measured with questionnaires: EQ-5D, DQL-BCl and DSC-R.

Results. After prospective observation, patients described significant improvement in QoL (EQ-VAS, DSC-R). DQL-BCI score remained unchanged, although detailed analysis showed improvement in treatment satisfaction, improvement in the level of knowledge about diabetes and increase in diabetes-related pain. Conclusions. Our study confirms the improvement in HRQoL after insulin therapy introduction. The results

Address for correspondence: dr n. med. Marta Dudzińska Katedra Interny z Zakładem Pielęgniarstwa Internistycznego Uniwersytet Medyczny

ul. Jaczewskiego 8, 20-954 Lublin

Phone: $+48(81) 7425825$

Fax: +48 (81) 7244669

e-mail: m.dudzinska1@o2.pl

Clinical Diabetology 2015, 4, 6, 226-231

DOI: $10.5603 /$ DK.2015.0030

Received: 29.07.2015

Accepted: 29.10 .2015 should encourage to early implementation of intensification of treatment. (Clin Diabet 2015; 4, 6: 226-231)

Key words: type 2 diabetes, insulin therapy, Health Related Quality of Life, education, treatment satisfaction

\section{Introduction}

The three most difficult points during the diabetes type 2 treatment are: the moment of diabetes diagnosis, manifestation or diagnosis of complications and insulin therapy introduction. Without a doubt, each of these moments is difficult for patients, but introduction of insulin therapy seems to be the one that can be influenced the most by both physicians and patients. In case of many individuals, despite indications, the moment of intensification of treatment is delayed because of barriers to initiating insulin therapy, partially because of fear of deterioration of quality of life (QoL) [1]. In case of inappropriate glycaemic control this situation is very unfavourable, because adequate management is crucial to prevent or minimize the development of long-term complications among patients suffering from type 2 diabetes [2].

The aim of this study was to evaluate changes in QoL of patients with type 2 diabetes after insulin therapy introduction in prospective observation.

\section{Patients and methods}

The study involved 52 patients (30 F, average age $63.1 \pm 10.1$ ), hospitalized in the Department of Endocrinology, Public Hospital No 4 in Lublin, and treated at Diabetes Outpatients Clinic or District Diabetes 
Outpatient Clinic in Lublin, Poland. General inclusion criteria: type 2 diabetes duration of $\geq 6$ months, patient's physical and psychical health condition allowing independent questionnaire filling, patient's agreement. Detailed criteria: the minimum of 6-month treatment with oral anti-diabetic drugs (OAD group) and a decision of attending physician to start the insulin therapy. Reasons for intensification of treatment was in $76.5 \%$ of patients secondary failure of OAD and in $23.5 \%$ of patients contraindications for continuation of OAD; detailed information described elsewhere [3]. Baseline QoL assessment of study group was undertaken just before introduction of insulin therapy. Patients qualified for a temporary insulin administration, e.g. during the periprocedural period, were not included in the study. Patients from study group $8 \pm 1.5$ months after baseline assessment again filled questionnaires received on visits in outpatient clinic or distributed by post. The characteristic of the study population is shown in Table 1. Clinical data and valuation of metabolic control was described elsewhere $[3,4]$.

All patients before participating in the study gave written informed consent in compliance with principles of Declaration of Helsinki. The study had an observatory character, thus the researchers did not interfere with the diagnostic or therapeutic process.

For purposes of the study, the researcher applied the diagnostic survey method by using a questionnaire for general QoL EQ-5D, as well as two diabetes-specific questionnaires: Diabetes Quality of Life-Brief Clinical Inventory (DQL-BCI) and Diabetes Symptom ChecklistRevised (DSC-R).

The generic quality of life EQ-5D questionnaire consists of two parts: the EQ-5D descriptive system (scored as EQ-5D index - range from -0.461 to 1 , where 1 is perfect QoL) and the EQ visual analogue scale (EQ-VAS,

Table 1. Characteristics of study population

\begin{tabular}{lc}
\hline $\mathbf{N}$ & 52 \\
Age, mean (SD) & $63.1(10.1)$ \\
$\quad$ Range & $44-79$ \\
Women, $\mathbf{n}(\%)$ & $30(57.7)$ \\
Men, $\mathbf{n}(\%)$ & $22(42.3)$ \\
Duration of diabetes, mean (SD) & $10.5(6.1)$ \\
$\quad$ Range & $1-25$ \\
BMI, mean (SD) [kg/m ${ }^{2}$ ] & $31.6(5.6)$ \\
Complications of diabetes, $\mathbf{n}(\%)$ & \\
Ischemic heart disease & $18(34.6)$ \\
Diabetic retinopathy & $4(7.7)$ \\
Diabetic neuropathy & $3(5.8)$ \\
Diabetic nephropathy & $5(9.6)$ \\
\hline
\end{tabular}

range $0-100$, where 100 is perfect health) $[5,6]$. The EQ-5D index results were calculated on the basis of Polish value set created by Golicki et al. [6].

Diabetes Quality of Life-Brief Clinical Inventory (DQL-BCI) is applied for the QoL assessment in cases of diabetes type 1 and 2 [7] created on the basis of one of the best known and most commonly used tools specific for diabetes - DQOL (designed for DCCT study) [8]. The total score is ranged 15 to 75 (75 is the best QoL) [9].

The DQL-BCl was standardized in English (US) and has never been used in Poland. The questionnaire's author gave his consent for its application and translation into Polish for use of the study, psychometric evaluation of the Polish version of DQL-BCl was described elsewhere [10]. To the best knowledge of authors the present study is first to use DQL-BCl in Europe and in Poland.

The Diabetes Symptom Checklist-Revised (DSC-R) is standardized, disease-specific questionnaire used for assessment QoL, especially in order to subjectively assess the frequency and strength of diabetes symptoms and their changes as a consequence of treatment among type 2 diabetes patients [11, 12]. The DSC-R consists of 34 items grouped into eight symptom subscales. Received scores are then transformed to a 0-100 score to obtain the DSC-R total score. The same transformation is applied to the DSC-R subscales. The higher score means the higher nuisance level and thus the worse QoL. The questionnaire was obtained in the Polish version [13].

\section{Statistical analysis}

The values of the considered parameters were measured in the nominal scale, characterised by means of multiplicity and proportion, as well as in the quotient scale, which referred to mean values and standard deviation with its variance. In order to compare two correlated groups the Wilcoxon signed-rank test was applied. A 5\% inference error and a significance level of $p<0.05$ were assumed, pointing to the existence of statistically significant differences or relationships. The statistical analysis was carried out using STATISTICA v. 8.0 software (StatSoft, Poland).

\section{Results}

After observation period, patients reported significant improvement in general QoL measured by EQ-VAS ( $p=0.002$ ) and close-to-significant improvement in EQ-5D index ( $p=0.07$ ). Slight positive tendency of improvement in QoL was recorded while using DQL-BCl, but the differences failed to reach statistical significance. Data presented in Table 2. In detailed analysis of chosen questions of $\mathrm{DQL-BCl}$, improvements in some aspects were identified. There was increase in the level 
Table 2. Quality of life scores

\begin{tabular}{|c|c|c|c|}
\hline Variable & $\begin{array}{l}\text { Before insulin therapy introduction } \\
\qquad n=52\end{array}$ & $\begin{array}{l}8 \pm 1.5 \text { months after insulin } \\
\text { therapy introduction, } n=52\end{array}$ & p-value ${ }^{1}$ \\
\hline EQ-5D index ${ }^{2}$ & $0.79 \pm 0.11$ & $0.81 \pm 0.1$ & 0.07 \\
\hline EQ-VAS ${ }^{2}$ & $53.0 \pm 15.0$ & $59.0 \pm 13.9$ & 0.002 \\
\hline DQL-BCI ${ }^{2}$ & $55.3 \pm 6.3$ & $56.8 \pm 7.1$ & 0.12 \\
\hline DSC-R total' ${ }^{2}$ & $29.3 \pm 14.5$ & $22.0 \pm 14.4$ & 0.00001 \\
\hline \multicolumn{4}{|l|}{ DSC-R domains } \\
\hline Psychological fatigue 2 (P-F) & $41.2 \pm 23$ & $31.7 \pm 22.4$ & 0.00004 \\
\hline Psychological cognitive ${ }^{2}(\mathrm{P}-\mathrm{C})$ & $26.2 \pm 20.6$ & $18.2 \pm 20.3$ & 0.00004 \\
\hline Neuropathic pain² (N-P) & $30.0 \pm 24.4$ & $21.3 \pm 21.2$ & 0.00002 \\
\hline Neuropathic sensoric ${ }^{2}$ (N-S) & $25.1 \pm 21.3$ & $15.6 \pm 16.2$ & 0.00002 \\
\hline Cardiovascular $^{2}(\mathrm{C})$ & $31.7 \pm 22.4$ & $25.2 \pm 23.8$ & 0.00009 \\
\hline Ophtalmologic ${ }^{2}(0)$ & $23.7 \pm 20.8$ & $22.0 \pm 24.4$ & 0.03 \\
\hline Hypoglycaemic ${ }^{2}$ (Hypo) & $15.1 \pm 14.8$ & $24.0 \pm 17.7$ & 0.07 \\
\hline Hyperglycaemic ${ }^{2}$ (Hyper) & $41.4 \pm 25.0$ & $21.6 \pm 21.5$ & 0.00001 \\
\hline
\end{tabular}

${ }^{1}$ Wilcoxon signed-rank test; ${ }^{2}$ mean \pm SD

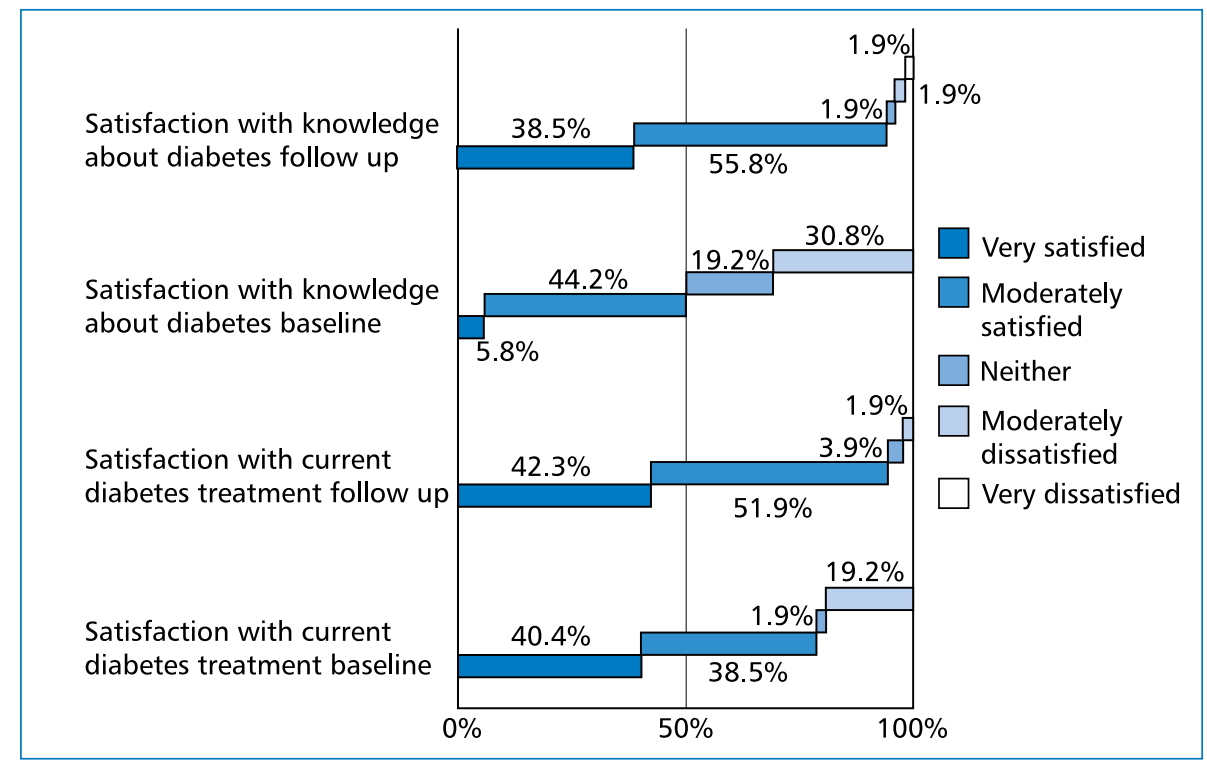

Figure 1. Comparison of chosen aspects of DQL-BCI before and after insulin therapy introduction

of patients' treatment satisfaction (percentage of patients who answered: very satisfied and moderately satisfied: baseline $78.9 \%$ vs follow-up $94.2 \%, p=0.03$ ) (Fig. 1). Besides studied group better assessed their satisfaction of level of diabetic knowledge (percentage of patients who answered: very satisfied and moderately satisfied: baseline $50 \%$ vs follow-up $94.2 \%, p<0.001$ ) (Fig. 1). Simultaneously a negative tendency was noticed - increased level of patient-reported pain related with treatment of diabetes (percentage of patients who pointed occurrence of pain: sometimes, often and all the time: baseline $9.6 \%$ vs follow-up $26.5 \%$, $p=0.0001$ ) (Fig. 2).
After insulin therapy introduction the patients assessed as significantly better their QoL related to presence and nuisance of diabetes related symptoms measured by DSC-R - in total score as well as in all subscales (Tab. 2, Fig. 3). The biggest improvement was observed in the subscale of hyperglycaemia $(p<0.001)$. Simultaneously close-to-significant increase in nuisance of hypoglycaemia related symptoms was registered ( $p=0.07$ ).

Furthermore treatment modification resulted in significantly better glycaemic control (baseline $\mathrm{HbA}_{1 \mathrm{c}}=7.9 \pm$ $\pm 1.3 \%$, vs follow-up $\mathrm{HbA}_{1 \mathrm{c}}=7.5 \pm 1.4 \%, \mathrm{p}=0.005$ ) without simultaneous weight gain (baseline $\mathrm{BMI}=31.8$, after $8 \pm 1.5$ months $\mathrm{BMI}=31.9, \mathrm{p}=0.6$. 


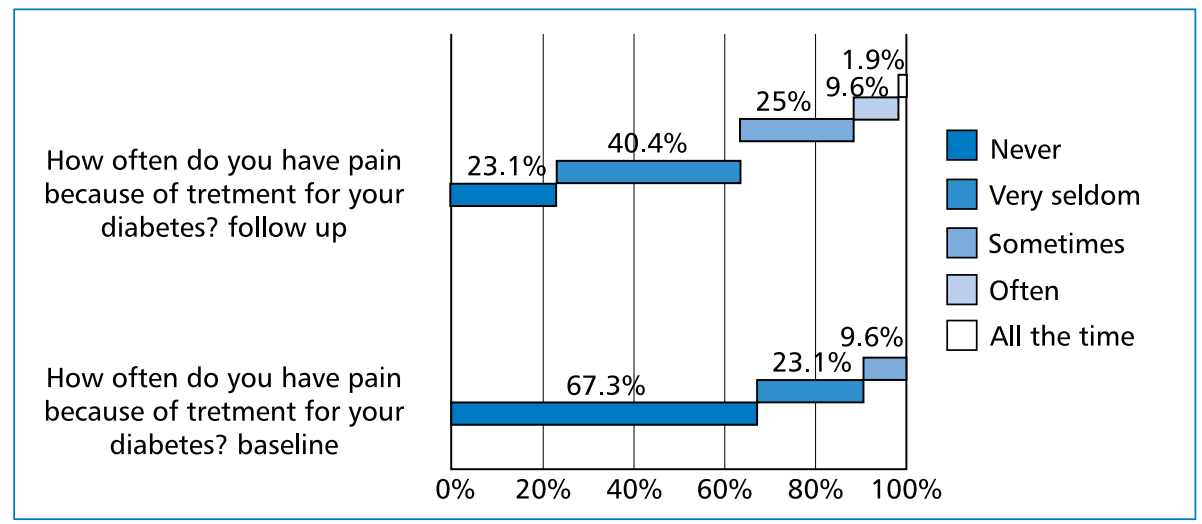

Figure 2. Patient-reported pain connected with diabetes treatment - before and after insulin therapy introduction

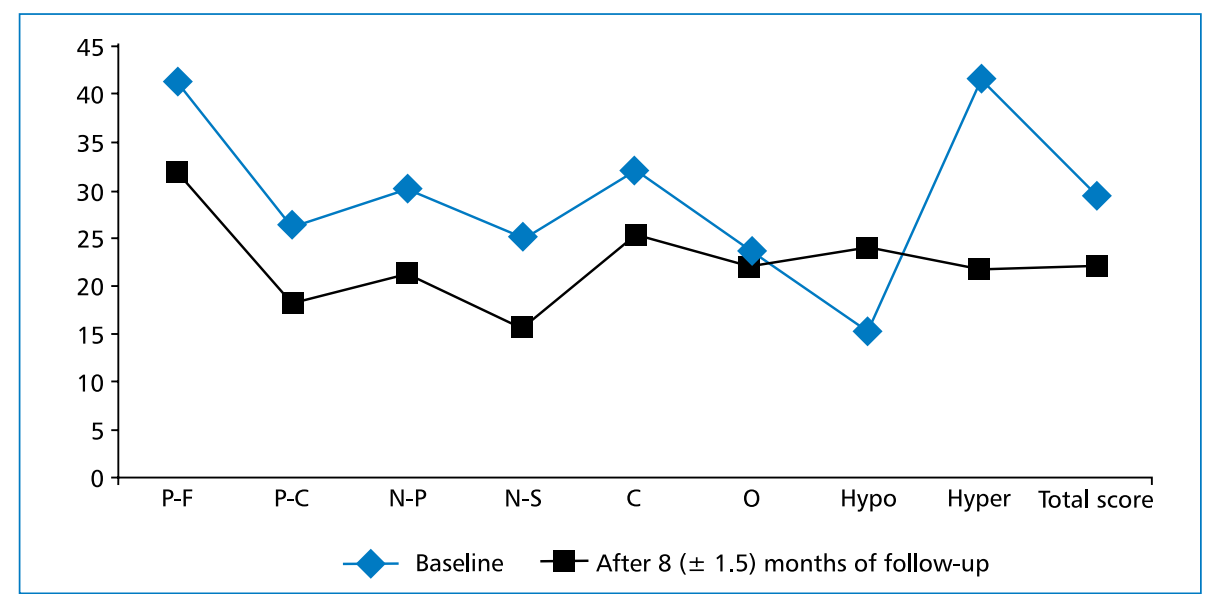

Figure 3. DSC-R results - total score and subscales. P-F - Psychological fatigue subscale; P-C - Psychological cognitive subscale; $\mathrm{N}-\mathrm{P}$ - Neuropathic pain subscale; N-S - Neuropathic sensory subscale; C - Cardiovascular subscale; O - Ophthalmologic subscale; Hypo - Hypoglycaemic subscale; Hyper - Hyperglycaemic subscale

\section{Discussion}

In presented study, after insulin therapy introduction there was observed improvement in general QoL as well as QoL measured by disease-specific tool (DSC-R). In all subscales of DSC-R questionnaire describing influence of diabetes-related symptoms on patients' QoL, a clear improvement was registered, which indicates smaller burden of disease symptoms. Particularly strong improvement was recorded in area of severity of hyperglycaemia symptoms, which was caused by better glycaemic control. These remarks have crucial meaning, especially when taking into account reports pointing out hyperglycaemia as independent factor strongly decreasing QoL $[14,15]$. The aim of therapy intensification is to achieve satisfactory glycaemic control and to limit hyperglycaemia occurrences; as a result there is a real possibility of improving patients' QoL and treatment satisfaction after the insulin therapy introduction, which is reflected by the results of presented study as well as was proved by other authors [14, 16-18]. Similar results yielded studies by other authors [1, 19].

Only slight improvement in EQ-5D index parameter may be caused by low sensibility of generic QoL tools for detecting changes in progress of treatment. Diabetes-specific DQL-BCl total score among our patients remained similarly unchanged. However detailed analysis proved increase in treatment satisfaction and satisfaction in level of knowledge connected with diabetes. Simultaneously increase in pain related burden was noted. Lack of change in QoL assessment measured with mentioned above scale was probably the result of counterbalance of positive and negative effects of therapy. It is also worth pointing out that a minimal increase in occurrence of hypoglycaemia related burden was observed (DSC-R), what is not surprising given the fact that it very often 
accompanies insulin usage. An appropriate adjustment of insulin therapy to patient's needs and an individual approach in treatment goals in type 2 diabetes, especially among older patients, is the subject to widespread discussion $[20,21]$ and helps to avoid hypoglycaemia and to decrease treatment-related pain.

Education as well as increased level of support and attention from medical personnel and patients' family during treatment intensification positively influences patients psychic condition, reduces fear of new treatment and gives a feeling of control over the disease. In case of most patients, these advantages are greater or at least balance all disadvantages of insulin therapy [17], which suggests the necessity of long-term support and periodical training programs for insulin treated patients [17].

As shown by the UKPDS study [2] and other analyses [22], worse quality of life results not from the therapy intensification but mainly from unsatisfactory glycaemic control and complications. Many widely recognized studies proved that the poor metabolic control is a factor greatly contributing to the development of macro- and microvascular complications $[2,21]$. Therefore, it would be advisable to intensify a therapy in order to curb the development of such complications and thus to restrain worsening of patients' QoL, which could otherwise deteriorate to a degree that exceeds all inconveniencies of daily injections.

Results of several researches $[14,17,18,23]$, which prove that patients' QoL improved after the intensification of treatment, as well as the results of our study should serve as encouragement for an introduction of insulin therapy at an earlier stage of type 2 diabetes than it is currently done.

This study was performed in everyday clinical practice and with wide Health Related Quality of Life (HRQoL) assessment by using three complementary tools, which were advantages of the research. One of QoL questionnaire (DQL-BCl) was translated and validated to use in presented study [10].

Limitation of the study is small quantity of patients and relatively short period of observation. Continuation of follow-up and assessment of wider group of individuals would be a goal for authors in near future.

\section{Conclusions}

1. Prospective observation of patients proved that insulin therapy yielded better QoL assessment results. Furthermore, there was a significant improvement in patients' treatment satisfaction and satisfaction from their knowledge about diabetes. The results should encourage to early implementation of intensification of treatment.
2. Negative outcomes of insulin therapy introduction were: greater exposure to treatment related pain and higher frequency of hypoglycaemia occurrence. This results point out the need of constant and repeatedly conducted education program for patients that should teach ways of preventing and dealing with hypoglycaemia.

\section{Acknowledgment}

Conflict of interest: none declared

\section{REFERENCES}

1. Vinik A. Advancing therapy in type 2 diabetes mellitus with early, comprehensive progression from oral agents to insulin therapy. Clin Ther 2007: 29: 1236-1253.

2. U.K. Prospective Diabetes Study Group: Quality of life type 2 diabetic patients is affected by complications but not by intensive polices to improve blood glucose or blood pressure control (UKPDS37). Diabetes Care 1999; 22: 1125-1136.

3. Dudzińska M, Tarach JS, Malicka J, Kurowska M, Kowalczyk M, Nowakowski A. Why, when and how insulin therapy is being started for patients with type 2 diabetes treated with oral medications: an observation study. Experimental and Clinical Diabetology 2011; 11: 45-50.

4. Dudzińska M, Kurowska M, Tarach JS, Malicka J, Nowakowski A. Kontrola metaboliczna i realizacja zaleceń PTD przed wdrożeniem i po wdrożeniu insulinoterapii u chorych na cukrzycę typu 2. Diabetol Prakt 2011; 12: 21-27.

5. Szende A, Williams A. Measuring Self-Reported Population Health: An International Perspective based on EQ-5D. EuroQol Group. SpringMEDPublishing; 2004.

6. Golicki D, Jakubczyk M, Niewada M, Wrona W, Busschbach JJ. Valuation of EQ-5D health states in Poland: first TTO-based social value set in Central and Eastern Europe. Value Health 2010; 13: 289-297.

7. Burroughs TE, Desikan R, Waterman BM, Gilin D, McGill J. Development and validation of the diabetes quality of life brief clinical inventory. Diabetes Spectrum 2004; 17: 41-49.

8. Jacobson AM, De Groot M, Samson JA. The evaluation of two measures of quality of life in patients with type I and II diabetes. Diabetes Care 1994; 17: 267-274.

9. Burroughs TE. Development and Validation of Diabetes Quality of Life- Brief Clinical Inventory. Administrator's Manual, v. 3.2. Saint Louis: Saint Louis University Center for Outcomes Research 2006: 1-28.

10. Dudzińska M, Tarach JS, Burroughs TE, Zwolak A, Matuszek B Smolen A, Nowakowski $A$. Validation of the Polish version of Diabetes Quality of Life - Brief Clinical Inventory (DQL-BCI) among patients with type 2 diabetes. Archives of Medical Science 2014; 10: 891-898.

11. Grootenhuis PA, Snoek FJ, Heine RJ, Bouter LM. Development of type 2 Diabetes Symptom Checklist: a Measure of Symptom Severity. Diabetic Medicine 1994; 11: 253-261.

12. Arbuckle RA, Humphrey L, Vardeva K et al. Psychometric Evaluation of the Diabetes Symptom Checklist-Revised (DSC-R) - A Measure of Symptom Distress. Value in Health 2009; 12: 1168-1175.

13. http://www.mapi-trust.org.

14. Hajos TR, Pouwer F, deGrooth R et al. Initiation of insulin glargine in patients with Type 2 diabetes in suboptimal glycaemic control positively impacts health-related quality of life. A prospective cohort study in primary care. Diabet Med. 2011; 28: 1096-1102.

15. Kleefstra N, Ubink-Veltmaat LJ, Houweling ST, Groenier KH, Meyboom-de Jong B, Bilo HJ. Cross-sectional relationship between glycaemic control, hyperglycaemic symptoms and quality of life in type 2 diabetes (ZODIAC-2). Neth J Med 2005; 63: 215-221. 
16. de Grauw WJ, van de Lisdonk EH, van Gerwen WH et al. Insulin therapy in poorly controlled type 2 diabetic patients: does it affect quality of life? British Journal of General Practice 2001; 51: 527-532.

17. Davis TM, Clifford RM, Davis WA. Effect of insulin therapy on quality of life in type 2 diabetes mellitus: The Fremantle Diabetes Study. Diabetes Research and Clinical Practice 2001; 52: 63-71.

18. Sieradzki J, Nazar M. Intensyfikacja leczenia insuliną w Polsce. Wyniki badania podstawowych parametrów wyrównania cukrzycy i satysfakcji z leczenia w dużej populacji chorych na cukrzycę typu 2. Diabetologia Praktyczna 2004; 5: 173-182.

19. Opsteen C, Qi Y, Zinman B, Retnakaran R. Effect of short-term intensive insulin therapy on quality of life in type 2 diabetes. J Eval Clin Pract 2012; 18: 256-261.
20. Bonds DE, Miller ME, Bergenstal RM et al. The association between symptomatic, severe hypoglycaemia and mortality in type 2 diabetes: retrospective epidemiological analysis of the ACCORD study. BMJ 2010; 340: b4909.

21. Available from: http://www.ncbi.nlm.nih.gov/pubmed/20061358.

22. The ADVANCE Collaborative Group. Intensive blood glucose control and vascular outcomes in patients with type 2 diabetes. NEJM 2008; 358: 2560-2572.

23. Testa MA, Simonson DC. Health economic benefits and quality of life during improved glycemic control in patients with type 2 diabetes mellitus: a randomized, controlled double blind trial. JAMA 1998; 280: 1490-1496.

24. Peyrot M, Rubin RR, Chen X, Frias JP. Associations between improved glucose control and patient-reported outcomes after initiation of insulin pump therapy in patients with type 2 diabetes mellitus. Diabetes Technol Ther 2011; 13: 471-476. 